\title{
Non-fluorine surface modification of acetylated birch for improved water repellence
}

\author{
Haiyan Yin *,a,b, Maziar Sedighi Moghaddam a , Mikko Tuominen a \\ Andra Dėdinaite ${ }^{\mathrm{c}, \mathrm{d}}$, Magnus Wålinder ${ }^{\mathrm{b}}$, and Agne Swerin ${ }^{*}$,d,e \\ ${ }^{a}$ RISE Research Institutes of Sweden, Division Bioeconomy and Health, Material and Surface \\ Design, Box 5607, SE-11486 Stockholm, Sweden \\ ${ }^{\mathrm{b}}$ KTH Royal Institute of Technology, School of Architecture and the Built Environment, Department \\ of Civil and Architectural Engineering, Division of Building Materials, SE-10044 Stockholm, \\ Sweden \\ ${ }^{c}$ RISE Research Institutes of Sweden, Division Bioeconomy and Health, Chemical Process and \\ Pharmaceutical Development, Box 5607, SE-11486 Stockholm, Sweden \\ ${ }^{\mathrm{d}}$ KTH Royal Institute of Technology, School of Engineering Sciences in Chemistry, Biotechnology \\ and Health, Department of Chemistry, Division of Surface and Corrosion Science, SE-10044 \\ Stockholm, Sweden \\ ${ }^{\mathrm{e}}$ Karlstad University, Faculty of Health, Science and Technology, Department of Engineering and \\ Chemical Sciences, Chemical Engineering, SE-65188 Karlstad, Sweden
}

*Corresponding author: haiyan.yin@ri.se, aswerin@kth.se

\begin{abstract}
In this work, a non-fluorinated surface treatment, i.e., hydrophobized silicone nanofilaments, was applied on both birch and acetylated birch wood samples via a gas-phase based reaction. A superhydrophobic behavior was observed on both the surface-modified samples as revealed by the static water contact angles greater than $160^{\circ}$, also valid for samples prepared with the shortest reaction time of $1 \mathrm{~h}$. The dynamic wettability behavior of the samples was studied by a multicycle Wilhelmy plate method. The surface-modified acetylated birch exhibited a pronounced enhanced water resistance, resulting in very low water uptake of $3 \pm 1 \mathrm{wt} \%$ after 100 cycles, which was about 29, 5 and 3 times lower than that of the birch, acetylated birch and surface-modified birch, respectively. Moreover, the aesthetic appearance of the acetylated wood was maintained as the surface modification only resulted in a small color change. This work shows the potential of preparing super water-repellent wood by non-fluorinated surface modification.
\end{abstract}

Keywords: non-fluorine surface modification, acetylated wood, silicone nanofilaments, superhydrophobic coating, multicycle Wilhelmy plate method 


\section{Introduction}

Owing to its renewability and sustainable forestry, wood is today the most abundant and low-carbon emitting material for large scale uses in the construction and furniture industries. Due to its hydrophilic nature, wood-based products are, however, susceptible to dimensional deformation and biological degradation, especially in outdoor applications. Improving the water-resistance of wood-based products has therefore gained increased attention in recent years (Cademartori et al. 2017, Hill (2006), Källbom et al. 2018, Meyer-Veltrup et al. 2017).

One approach for improving the water-resistance of wood is by modifying the wood via acetylation, in which the accessible hydroxyl groups in the wood cell-wall react with acetic anhydride and form ester bonds (Rowell et al. 1994). It is reported that the equilibrium moisture content of acetylated pine is reduced to $8.4 \%$ at $90 \%$ $\mathrm{RH}$, which is 2.6 times lower than that of non-acetylated pine (Rowell 2014). Apart from the increased moisture resistance, the acetylated wood shows improved physical, mechanical and biological properties (Bongers et al. 2019, Chai et al. 2017). Moreover, the acetylation process can be defined as a non-toxic chemical treatment. Therefore, there has been a growing interest in using acetylated wood for improving the performance of wood in recent years (Beck et al. 2018, Hansmann et al. 2004, Hung et al. 2016, Joffre et al. 2017, Laine et al. 2016, Ringman et al. 2020). However, studies show that acetylation of wood only increases the apparent water contact angle to a minor extent, e.g. from $69^{\circ}$ to $83^{\circ}$ (Bryne et al. 2010), which suggests that the wood is still prone to interaction with moisture, thus increasing the risk e.g. for surface discoloration and mold growth.

Another approach is to modify wood surfaces by a superhydrophobic layer. Superhydrophobic surfaces, inspired by the lotus leaf structure, show non-wettability and good self-cleaning properties when in contact with water. A superhydrophobic layer on wood can be achieved by combining a nanoscale structure with low surface energy chemistry on top (Teisala et al. 2018, Tuteja et al. 2011, Wang et al. 2020). Usually, nanoparticles such as $\mathrm{SiO}_{2}, \mathrm{ZnO}$ and $\mathrm{TiO}_{2}$ are used to create the nanoscale roughness on wood surfaces (Gao et al. 2015, Guo et al. 2017, Pandit et al. 2020, Sedighi Moghaddam et al. 2016, Tuominen et al. 2016). For example, Pandit et al. (Pandit et al. 2020) report a superhydrophobic coating on wood prepared by $\mathrm{TiO}_{2}$ nanoparticles and perfluorooctyltriethoxysilane. The modified wood exhibits excellent repellence towards water and liquids with lower surface tension. In our previous work (Yin et al. 2020), we showed that fluorinated silicone nanofilaments 
layers could improve the liquid repellence of wood surfaces, leading to high static contact angles and low liquid uptake rate and level towards water, ethylene glycol and hexadecane. Silicone nanofilaments layer is a promising surface modification method for improving the water-resistance of wood by ultra/superhydrophobization via micro- and nano-scale surface roughness of wood and low surface energy chemistry. Moreover, no extra reagents are involved in the gas-phase based reaction, thus reducing possible negative effects to the environment during the modification process.

A superhydrophobic surface is not a barrier for vapor from diffusing through an air layer into a hygroscopic substrate (Swerin et al. 2009, Yin et al. 2020). Therefore, even though superhydrophobic surfaces repel water, the final liquid uptake of the surface-modified wood can still be high as a result of liquid diffusion, and plausibly solubility, into the hygroscopic substrate. This effect shows that the application of a superhydrophobic coating to improve the liquid repellence of wood is still limited.

A superhydrophobic layer improves the water repellence of wood surfaces; acetylation, on the other hand, reduces the number of the hydroxyl groups in the wood substance, thus reducing its affinity for water sorption. This encouraged our study whether such a combination, i.e. applying a superhydrophobic layer on the acetylated wood, can lead to a significantly enhanced liquid resistance of wood. To our knowledge, no previous work has investigated this combination of bulk and surface modification.

In this work, we applied the silicone nanofilaments on acetylated wood surfaces through a gas-phase based silicone nanofilaments preparation method at reduced pressure. To reduce the potential hazard to environmental and human health, a nonfluorinated alkylsilane is utilized in the following hydrophobization process. Apart from the static contact angle measurement, the dynamic wettability of the surfacemodified wood was studied by a multicycle Wilhelmy plate method. This work shows the possibility of achieving extremely low water uptake of wood using a nonfluorinated surface modification approach.

\section{Materials and methods}

Materials: The birch veneers were provided by Koskisen Oy in Finland. Half of the received birch veneers were acetylated by Accsys in Arnhem, the Netherlands, according to the process described on their webpage (Accsys). The acetyl content of the acetylated birch veneers was above $20 \%$. The dimensions of the birch and 
acetylated birch wood samples used in this work were in approximately $30 \times 20 \times 1$ $\mathrm{mm}^{3}$ in the longitudinal, tangential and radial directions $(\mathrm{L} \times \mathrm{T} \times \mathrm{R})$, respectively. The average moisture content was 5 and $1.4 \%$, respectively, for the birch and acetylated birch.

Wood surface modification: The birch and acetylated birch wood samples were first surface-modified by silicone nanofilaments at reduced pressure. The schematic illustration of the reaction setup for preparing silicone nanofilaments is shown in Figure 1a. Specifically, the wood samples (a total surface area of around $70 \mathrm{~cm}^{2}$ for each type) were placed together with a vial containing $300 \mu \mathrm{L}$ of trichloromethylsilane (TCMS, 99\%, Sigma-Aldrich) and a vial containing $75 \mu \mathrm{L}$ of water (Type 1, Milli-Q) in a sealed desiccator (reaction chamber, ca 5.7 L), which was connected to a rotary vane vacuum pump (Edwards). The reaction chamber was evacuated to the pressure of $5 \mathrm{kPa}$ before the reaction started. The samples with a reaction time of 1, 2, 5 and $20 \mathrm{~h}$ were prepared. Figure $1 \mathrm{~b}$ shows the RH change in the reaction chamber, which was measured by placing a hygrometer (Testo 174) together with the water in the chamber. The moisture absorption capacity for acetylated birch wood and birch wood is different. Therefore, to ensure the same RH changes in the synthesis of silicone nanofilaments, acetylated and non-acetylated wood samples were placed in the chamber together.

To further reduce the surface energy, the silicone nanofilaments coated samples were hydrophobized by chemical vapor deposition of trichloro(octyl)silane (TCOS, $97 \%$, Sigma-Aldrich) for $2 \mathrm{~h}$ in a second step. Prior to the second step, the samples were plasma-activated in an $18 \mathrm{~W}$ air plasma cleaner (PDC-3XG, Harrick) for $5 \mathrm{~min}$. In this process, the hydrophobic methyl groups of the silicone nanofilaments on the surfaces were converted into hydrophilic hydroxyl groups, which facilitated the bonding of TCOS molecules on the surface in the second step. The surface-modified birch and acetylated birch samples are denoted SMB and SMAB, respectively.

Characterization: Scanning electron microscopy (SEM) (FEI Quanta FEG 250) was utilized for imaging of the wood surfaces. The SEM characterization was performed at an accelerating voltage of $10 \mathrm{kV}$ with a working distance of $10 \mathrm{~mm}$ in a low vacuum mode (LV-SEM) of $7 \mathrm{kPa}$. No surface pre-coating was applied. The diameter distribution of the silicone nanofilaments was calculated by analyzing the SEM images of the SMB and SMAB wood using ImageJ software. At least 1000 nanofilaments were chosen in the calculation for each sample. Fourier-transform infrared spectroscopy (FTIR) (Spectrum One, Perkin Elmer) equipped with an attenuated total reflection was used to study the chemical compositions on the wood 
surfaces. All spectra were recorded between 4000 and $400 \mathrm{~cm}^{-1}$ at a resolution of 4 $\mathrm{cm}^{-1}$ and 16 scans per sample.

The color of the wood samples was measured using an optical spectrophotometer X-Rite SP60 D65/10 illumination. The CIE LAB color space coordinate system was used to evaluate the color changes of the wood samples after the surface modification. Three parameters, viz., $L^{*}, a^{*}$ and $b^{*}$ were recorded, where $L^{*}$ represents lightness ( $L^{*}=100$ for pure white, $L^{*}=0$ for total blackness); $+a^{*}$ represents redness while $a^{*}$ for green; $+b^{*}$ represents yellowness while $-b^{*}$ for blue. The total color change $\left(\Delta E^{*}\right)$ was calculated according to the equation:

$$
\Delta E^{*}=\sqrt{\Delta L^{* 2}+\Delta a^{* 2}+\Delta b^{* 2}}
$$

where $\Delta L^{*}, \Delta a^{*}$, and $\Delta b^{*}$ are the differences between the color of the wood samples before and after the surface modification. At least 8 spots were analyzed for each sample.

The wettability of the wood and surface-modified wood was studied using an optical contact angle goniometer (OCA40, DataPhysics) equipped with a high-speed CCD camera $\left(\max 2200\right.$ images $\left.\mathrm{s}^{-1}\right)$. Measurements were performed in a climatecontrolled room of $50 \pm 3 \% \mathrm{RH}$ at $23 \pm 1^{\circ} \mathrm{C}$. A water drop of $10 \mu \mathrm{L}$ was chosen as the surface-modified wood was superhydrophobic and drops of a smaller volume could not be dispensed on the surfaces. The tilting speed of the roll-off angle measurement was $1.58^{\circ} \mathrm{s}^{-1}$. The static contact angles (CAs) and roll-off angles (ROAs) of water (Type 1, Milli-Q, surface tension $72.3 \pm 0.2 \mathrm{mN} \mathrm{m}^{-1}$ ) were determined by the SCA 20 (DataPhysics) software using Young-Laplace fitting. At least 10 droplets were analyzed in each case.

A Sigma 70 tensiometer from KSV Instruments (now Biolin Scientific) was used for measuring the wetting properties and water uptake of the unmodified and surfacemodified wood samples. The measurements followed a previously developed method (Sedighi Moghaddam et al. 2013, Sedighi Moghaddam et al. 2016). Specifically, a 100 -cycle Wilhelmy plate measurement was performed with the wood veneer in water. The immersion and withdrawal velocity of the veneer was $12 \mathrm{~mm} \mathrm{~min}^{-1}$. The immersion depth was $10 \mathrm{~mm}$ and the withdrawing position was $5 \mathrm{~mm}$ above the water. To prevent end-grain water penetration and fast longitudinal liquid transportation during measurement, the cross section of the tested wood veneer was coated by polyurethane lacquer before the measurement. Based on the immersion depth and the immersion and withdrawal velocity of the veneer, the wood veneer contacted with the water for a total of ca 167 min during the 100 cycles. 
For porous and hygroscopic samples like wood, the measured force $F$ can be written as (Wålinder et al. 2001):

$$
F(h, t)=P \gamma \cos \theta+F_{w}(t)-\rho A h g
$$

where $P \gamma \cos \theta$ equals the wetting force and $P$ is the wetted perimeter of the wood veneer, $\gamma$ the surface tension of the probe liquid, and $\theta$ the liquid-solid-air contact angle; $\rho A h g$ corresponds to the buoyancy force and $\rho$ is the probe liquid density, $A$ the cross-sectional area of the veneer, $h$ the immersion depth, $g$ the gravitational constant and $F_{w}(t)$ the force due to sorption of the liquid at time $t$. The advancing angle $\theta_{a}$ and receding angle $\theta_{r}$ at cycle $n$ can be obtained by linear regression of the corresponding curves extrapolated to zero depth $(h=0)$ in the multicycle Wilhelmy plate plot (cf. Figure 6), assuming that $P$ and $\gamma$ are constant, and Eq. 2 can be simplified to:

$$
\begin{gathered}
F_{a d, n}=P \gamma \cos \theta_{a, n}+F_{f, n-1} \\
F_{r e, n}=P \gamma \cos \theta_{r, n}+F_{f, n}
\end{gathered}
$$

where $F_{f, n-l}$ and $F_{f, n}$ are the final forces after cycle $n-1$ and $n$, respectively, which are caused by the sorption. The $F_{f, n-l}$ and $F_{f, n}$ are equal to the term $F_{w}(t)$ in Eq. 2 . The two contact angles at cycle $n, \theta_{a, n}$ and $\theta_{r, n}$, can be calculated as:

$$
\begin{aligned}
\cos \theta_{a, n} & =\frac{F_{a, n}-F_{f, n-1}}{P \gamma} \\
\cos \theta_{r, n} & =\frac{F_{r, n}-F_{f, n}}{P \gamma}
\end{aligned}
$$

Sorption is determined by linear regression of the final force, $F_{f}$, to zero depth for each cycle.

The liquid uptake of wood veneer after cycle $n, W_{n}$ is calculated as:

$$
W_{n}=\frac{F_{f, n}}{m g} \times 100 \%
$$

where $m$ is the initial mass of the wood sample before sealing.

\section{Results and discussion}

\section{Silicone nanofilaments preparation conditions}

The relative humidity $\mathrm{RH}$ in the reaction chamber affects the formation of polysiloxane nano- and microstructures in the gas-phase based reaction. The different preparation conditions lead to the formation of different structures, e.g., nanofilaments, microrods and mixtures of them (Artus et al. 2017). It has been shown that the silicone nanofilaments can form in a rather broad RH range, i.e., between $20 \%$ and $60 \% \mathrm{RH}$, at room temperature during the synthesis (Artus et al. 2017, Olveira et 
al. 2018). In this work, liquid water was used in the reaction chamber at reduced pressure. The liquid started evaporating upon reduction of pressure, which was accompanied by the increase of RH in the chamber. This process can produce a high $\mathrm{RH}$ in the chamber quickly, thus facilitating the growth of silicone nanofilaments.
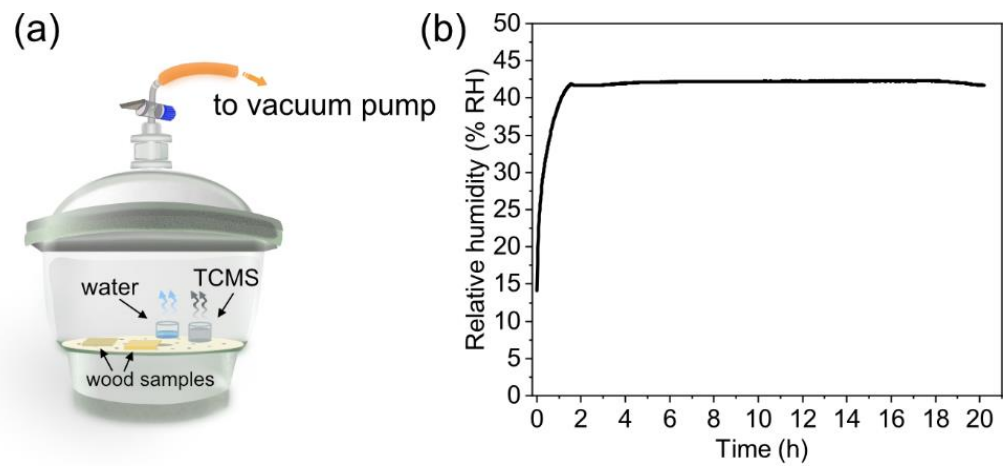

Figure 1. (a) Schematic illustration of the reaction setup for preparing silicone nanofilaments in gas phase at a reduced pressure of $5 \mathrm{kPa}$; (b) the corresponding relative humidity versus time in the reaction chamber with wood samples.

As can be seen in Figure 1b, the RH was low at start due to the removal of air in the reaction chamber at reduced pressure. It increased quickly to around $20 \% \mathrm{RH}$ in a few minutes due to the continuous evaporation of the water, which was suitable for the growth of silicone nanofilaments (Artus et al. 2014). The RH reached a plateau of around $40 \% \mathrm{RH}$ in 30 to $60 \mathrm{~min}$ which was ideal for the synthesis of silicone nanofilaments (Zimmermann et al. 2008).

\section{Morphology}

The surface morphology as seen by SEM and the silicone nanofilaments diameter distribution at the reaction times of 1, 2, 5 and $20 \mathrm{~h}$ for SMB and SMAB samples are shown in Figures 2 and 3, respectively. Silicone nanofilaments with large length-todiameter ratios were observed on both the SMB and SMAB wood surfaces already at short reaction times ( 1 and $2 \mathrm{~h}$ ). These structures were mainly located on the wood cell walls as indicated clearly in Figure $3 \mathrm{e}$. Some micrometer rods with relatively large diameters were observed as well. These microrods, which were mainly located on the wood cell walls and distributed sparsely, were present especially at short reaction times. Most of these structures completed their growth at $2 \mathrm{~h}$ and were less 
apparent at longer reaction times. The nanometer filament structures became the dominant structures when the reaction time was increased to $5 \mathrm{~h}$ and the coverage of the silicone nanofilaments on the wood surfaces increased accordingly. A dense silicone nanofilamental network was formed on both SMB and SMAB wood surfaces. Due to the heterogeneity of the wood surfaces, however, some areas were not covered with the silicone nanofilaments on both SMB and SMAB, even when the reaction time was increased to $20 \mathrm{~h}$. Since there is no obvious coverage change between 5 and $20 \mathrm{~h}$, we conclude that a reaction time of $5 \mathrm{~h}$ is sufficient for good silicone nanofilaments coverage on the wood surfaces when preparing the silicone nanofilaments at reduced pressure.
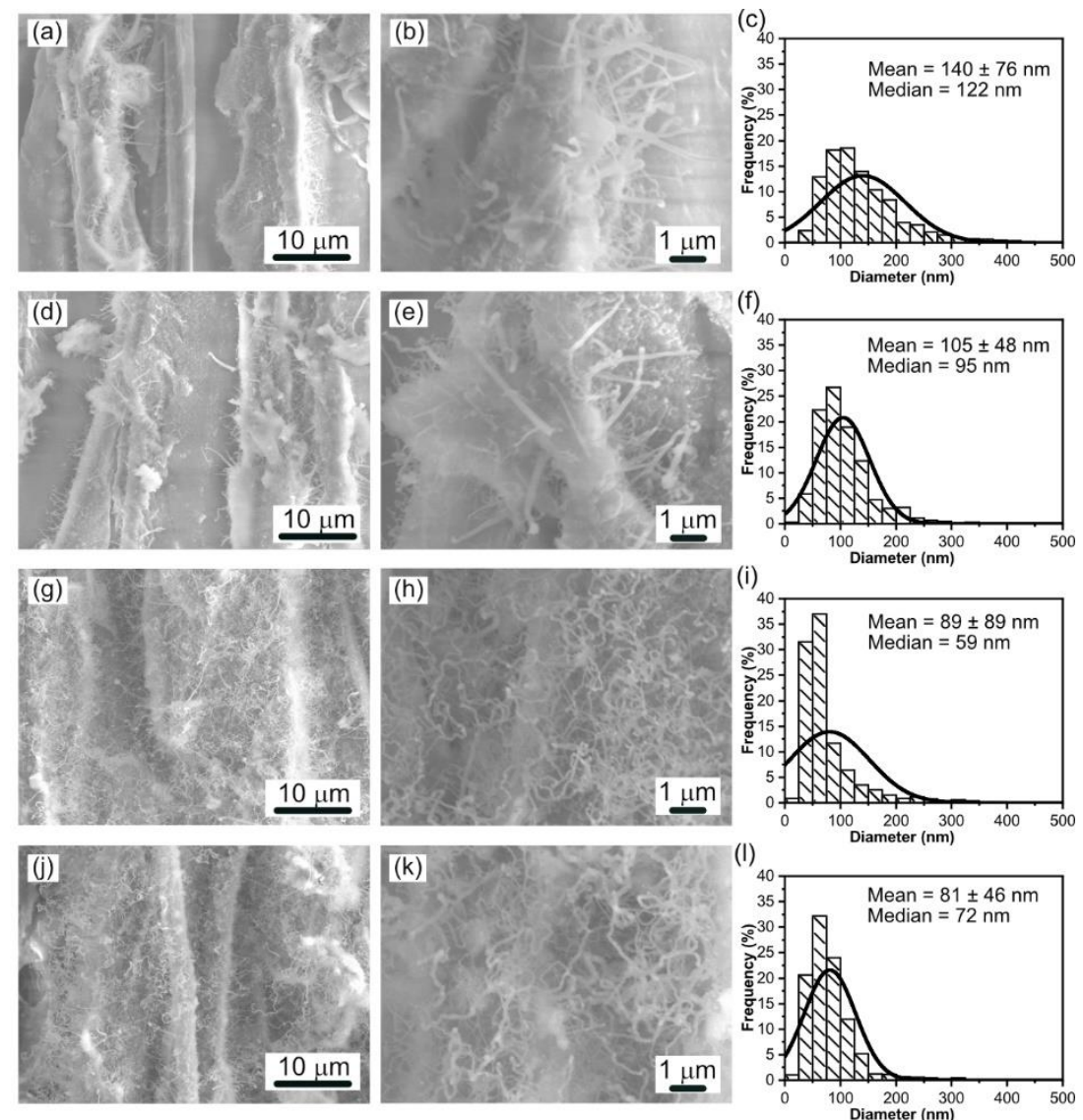

Figure 2. Top-view SEM images of SMB samples and the corresponding numberfrequency per $25 \mathrm{~nm}$ size class and normal distribution curve (fitted to the data) of the silicone nanofilaments on the surfaces at the reaction time of $(a, b, c) 1 \mathrm{~h},(\mathrm{~d}, \mathrm{e}, \mathrm{f})$ 
$2 \mathrm{~h},(\mathrm{~g}, \mathrm{~h}, \mathrm{i}) 5 \mathrm{~h}$ and $(\mathrm{j}, \mathrm{k}, \mathrm{l}) 20 \mathrm{~h}$. The average diameter with standard deviation and the median values of the polysiloxane structures on SMB at different reaction times are given.

The average diameter of silicone nanofilaments on both SMB and SMAB followed a similar change, i.e. it decreased with increasing reaction time. The differences between 5 and $20 \mathrm{~h}$ were, however, small since most of the silicone nanofilaments finished growing after $5 \mathrm{~h}$.
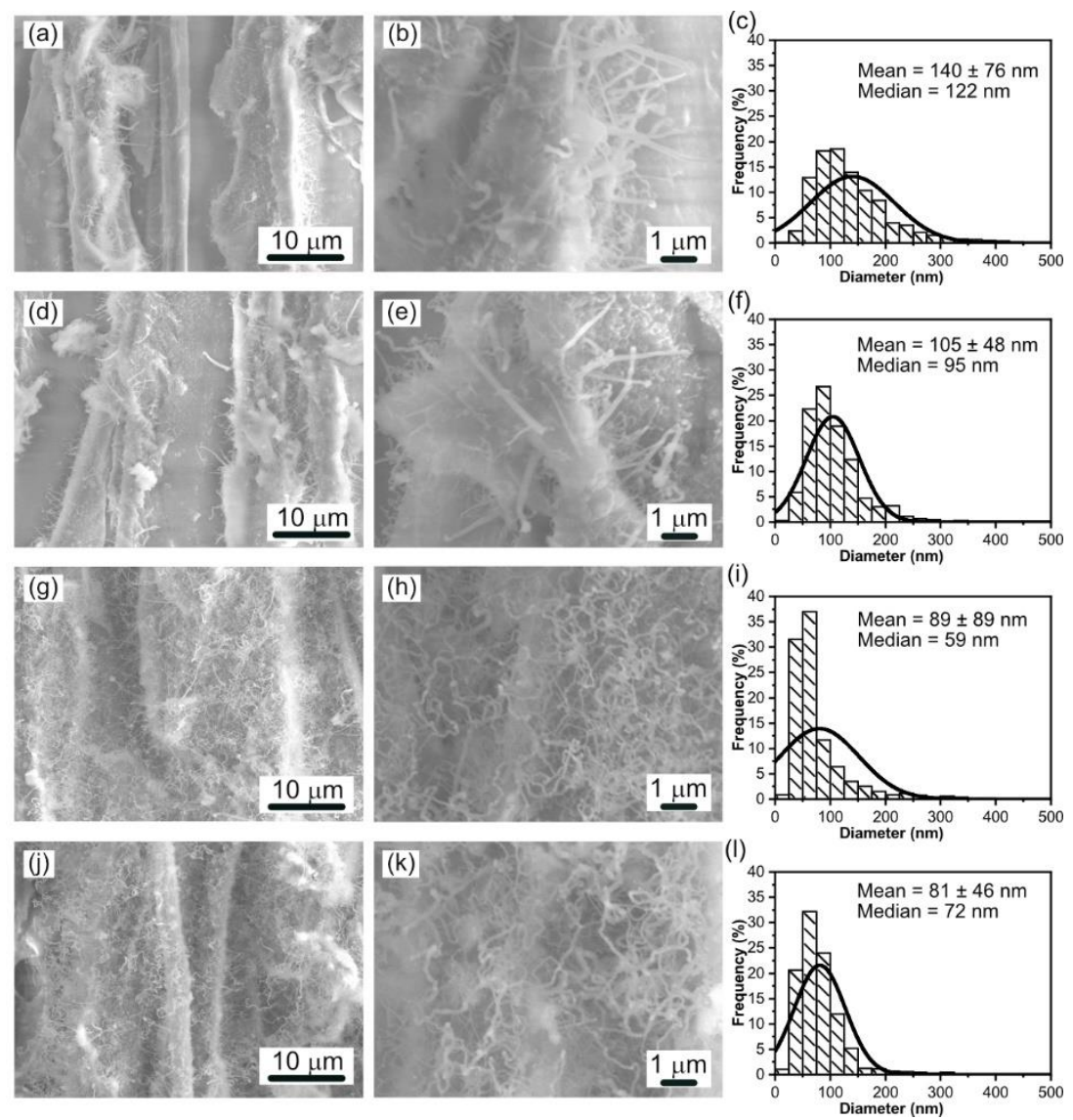

Figure 3. Top-view SEM images of SMAB samples and the corresponding numberfrequency per $25 \mathrm{~nm}$ size class and normal distribution curve (fitted to the data) of the silicone nanofilaments on the surfaces at the reaction time of $(a, b, c) 1 \mathrm{~h},(\mathrm{~d}, \mathrm{e}, \mathrm{f})$ $2 \mathrm{~h},(\mathrm{~g}, \mathrm{~h}, \mathrm{i}) 5 \mathrm{~h}$ and $(\mathrm{j}, \mathrm{k}, \mathrm{l}) 20 \mathrm{~h}$. The average diameter with standard deviation and 
the median values of the polysiloxane structures on SMAB at different reaction times are given.

It is usually regarded that the hydroxyl groups on the substrate are responsible for the growth of silicone nanofilaments on the substrate surface (Artus et al. 2014). As known, the freely accessible hydroxyl groups in the acetylated wood substance are reduced. There is however no obvious change in silicone nanofilaments distribution on the surfaces comparing SMB and SMAB samples prepared at the same time. This suggests that the decrease in accessible hydroxyl groups in the acetylated wood did not hinder the synthesis of silicone nanofilaments. On the other hand, the silicone nanofilaments with larger average diameters were observed on the SMAB at longer preparation times $(5$ and $20 \mathrm{~h}$ ), indicating that the decrease in accessible hydroxyl groups in wood can lead to a growth of the silicone nanofilaments in diameter.

\section{Surface chemistry}

The formation of the silicone nanofilaments on the surface-modified wood surfaces is confirmed by FTIR spectra in Figure 4. Since there were only small differences regarding the related absorption peaks, only the FTIR spectra of the surface-modified wood prepared at $5 \mathrm{~h}$ are shown. Two absorption peaks at 780 and $1270 \mathrm{~cm}^{-1}$ appeared for SMB and SMAB samples, which correspond to the stretching vibrations of Si-C bond and $-\mathrm{CH}_{3}$ deformation vibrations of the siloxane compounds, respectively (Cunha et al. 2010, Tang et al. 2016). An additional peak assigned to the $\mathrm{C}-\mathrm{H}$ bond from $\mathrm{Si}_{-} \mathrm{CH}_{3}$ was observed at $2969 \mathrm{~cm}^{-1}$ on SMB and SMAB. These results confirmed the successful synthesis of polysiloxane on the wood surface.

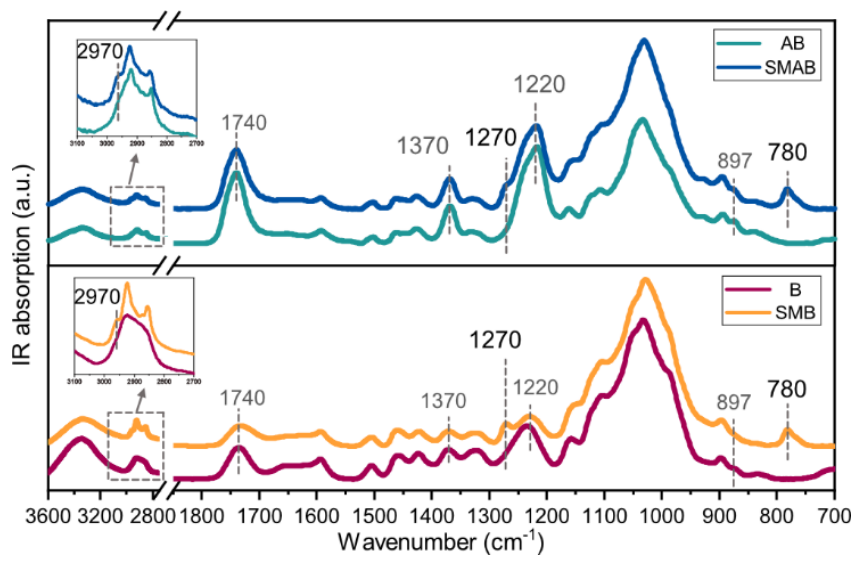


Figure 4. FTIR spectra of the birch (B), acetylated birch (AB) and SMB and SMAB samples prepared at $5 \mathrm{~h}$.

Apart from the peak changes related to the silicone nanofilaments, an obvious intensity increase was observed for the acetylated birch and SMAB samples at the absorption peaks of 1740, 1370, 1220 and $897 \mathrm{~cm}^{-1}$, which were assigned to the stretching of $\mathrm{C}=\mathrm{O}$ bonds, the deformational vibration of $\mathrm{C}-\mathrm{H}$ bonds in the methyl group, the stretching of $\mathrm{C}-\mathrm{O}$ bonds and the vibration of methyl groups, respectively (Mohammed-Ziegler et al. 2008, Pries et al. 2013). Since the acetylated wood could still absorb moisture, the reduction of the broad hydroxyl peak in the region of 3200 to $3500 \mathrm{~cm}^{-1}$ was less obvious.

\section{Color change}

Figure 5 shows the lightness and color changes of SMB and SMAB wood samples at different reaction times. The original color (OC) and final color (FC) after the surface modification (at silicone nanofilaments reaction time of 1 and $20 \mathrm{~h}$ ) of the wood samples are shown in Figure 5d. As shown, the color of SMAB wood varied in a small range regarding the three parameters, viz., $\Delta L^{*}, \Delta a^{*}$ and $\Delta b^{*}$. The $\Delta E^{*}$ was smaller than 2 at all reaction times, suggesting that the color change was not detectable by the naked eye (Barcík et al. 2015). On the contrary, the $\Delta L^{*}$ of the SMB wood surface shifted from -1.3 to -7.5 from reaction time 1 to $20 \mathrm{~h}$, which indicates that the surface becomes darker upon increasing reaction time. The $\Delta a^{*}$ and $\Delta b^{*}$ values also changed with the reaction time, but they were less obvious as the color change values were smaller than 3 . The $\Delta E^{*}$ increased with increasing reaction time and it was higher than 3 already at $2 \mathrm{~h}$. The $\Delta E^{*}$ increased to $8.4 \pm 0.6$ at $20 \mathrm{~h}$, suggesting the color change of SMB wood was clearly seen. From the inserted images of the wood samples in Figure 5d, it was obvious that SMB samples showed more color change after surface modification, especially at $20 \mathrm{~h}$. Therefore, the surface modification results in more color change for the non-acetylated wood than for the acetylated wood. 

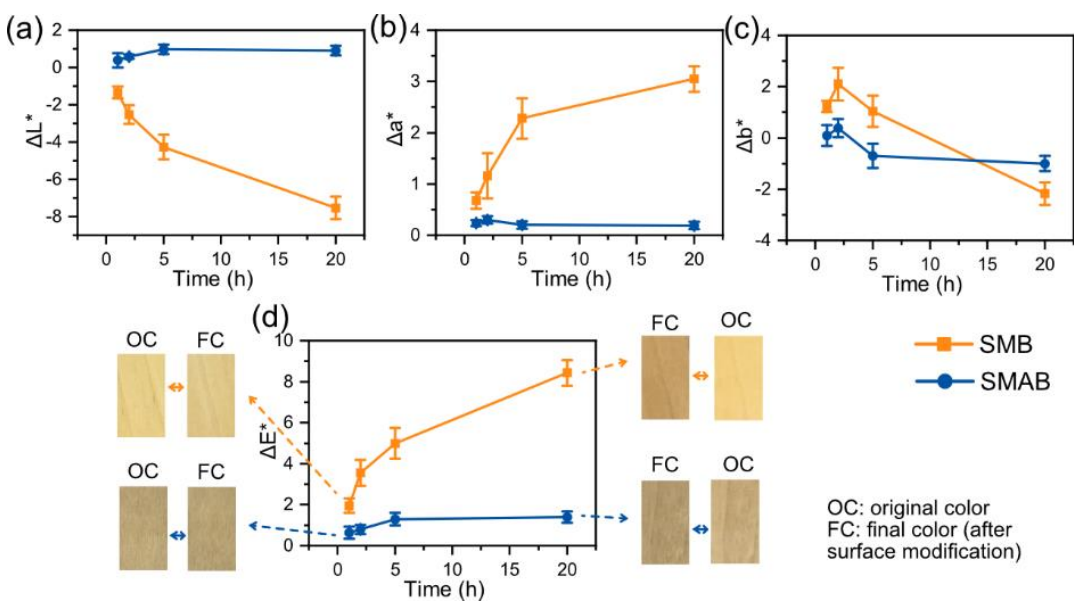

Figure 5. Changes in (a) lightness $\Delta L^{*}$, (b) redness $\Delta a^{*}$, and (c) yellowness $\Delta b^{*}$, and total color change $\Delta E^{*}$ of SMB and SMAB wood samples after the surface modification at different silicone nanofilaments reaction times. The original color (OC) and final color (FC) of wood samples prepared at 1 and $20 \mathrm{~h}$ are given in Figure $5 \mathrm{~d}$.

The color change of the wood samples is caused by the release of hydrochloric acid during the surface modification process. Acids can catalyze the condensation and degradation reactions in lignin structures and contribute to the discoloration of wood ((Chen et al. 2012, Lundquist 1970, Sundqvist (2004)). Since more lignin components in wood are modified in the acetylation process (Rowell et al. 1994), the color change of the acetylated wood in the surface modification is less obvious.

\section{Wettability}

Table 1 gives the CA and ROA of SMB and SMAB samples toward water at different reaction times. It should be mentioned that the results for SMB and SMAB samples can only partially represent the surfaces as only droplets that can be analyzed were considered. Due to the heterogeneity of wood surfaces, some drops rolled off immediately after dispensing while some other drops pinned on the surfaces. As shown in Table 1 , the birch and acetylated birch wood showed a CA of $59 \pm 7^{\circ}$ and $64 \pm 8^{\circ}$, respectively. The silicone nanofilaments coating increased the static contact angle significantly, resulting in a CA of $164 \pm 6^{\circ}$ and $163 \pm 5^{\circ}$, respectively, for the SMB and SMAB samples prepared at $1 \mathrm{~h}$. The silicone nanofilaments coating did not show an obvious difference between SMB and SMAB regarding the static contact 
angles. Values varying from $162^{\circ}$ to $164^{\circ}$ were observed for both the SMB and SMAB samples prepared at longer times, indicating the reaction time did not affect the static contact angles too much. On the other hand, the ROA of the SMAB sample decreased from $26 \pm 19^{\circ}$ at $1 \mathrm{~h}$ to $11 \pm 10^{\circ}$ at $20 \mathrm{~h}$, suggesting that the reaction time can improve the water repellence of the acetylated wood surfaces. However, this decreasing trend was not observed for the SMB sample. Given the fact that wood is heterogeneous, we conclude from high static CA and low ROA for the longer reaction time that the modified wood is superhydrophobic.

Table 1. Static water contact angles (CAs) and roll-off angles (ROAs) with standard deviations of SMB and SMAB at different reaction times. ${ }^{\mathrm{a}}$

\begin{tabular}{|c|c|c|c|c|c|c|}
\hline $\begin{array}{l}\text { Reaction } \\
\text { time }(\mathrm{h})\end{array}$ & $\begin{array}{c}\text { Sample } \\
\text { name }\end{array}$ & $\mathrm{CA}\left({ }^{\circ}\right)$ & $\begin{array}{c}\mathrm{ROA} \\
\left(^{\circ}\right)\end{array}$ & $\begin{array}{c}\text { Sample } \\
\text { name }\end{array}$ & $\mathrm{CA}\left({ }^{\circ}\right)$ & $\operatorname{ROA}\left({ }^{\circ}\right)$ \\
\hline 1 & \multirow{4}{*}{ SMB } & $164 \pm 6$ & $34 \pm 20$ & \multirow{4}{*}{ SMAB } & $163 \pm 5$ & $26 \pm 19$ \\
\hline 2 & & $162 \pm 5$ & $44 \pm 17$ & & $162 \pm 4$ & $26 \pm 7$ \\
\hline 5 & & $163 \pm 6$ & $26 \pm 16$ & & $164 \pm 4$ & $14 \pm 5$ \\
\hline 20 & & $163 \pm 3$ & 42 & & $163 \pm 5$ & $11 \pm 10$ \\
\hline & Birch & $59 \pm 7$ & $\mathrm{n} / \mathrm{a}$ & $\begin{array}{l}\text { Acetylated } \\
\text { birch }\end{array}$ & $64 \pm 8$ & $\mathrm{n} / \mathrm{a}$ \\
\hline
\end{tabular}

${ }^{a}$ Due to the heterogeneity of wood surfaces, some drops rolled off immediately after dispensing while some other drops pinned on the surfaces. The static contact angles were calculated based on the drops that did not roll off immediately after dispensing and the roll-off angles were calculated based on the drops that did not roll off immediately but rolled off at certain degrees. The specific information:

i) $1 \mathrm{~h}, 1 / 13$ of the dispensed drops rolled off immediately while $2 / 13$ of the dispensed drops pinned on the SMB surfaces; $1 / 11$ of the dispensed drops rolled off immediately while $3 / 11$ of the dispensed drops pinned on the SMAB surfaces;

ii) $2 \mathrm{~h}, 9 / 13$ of the dispensed drops pinned on the SMB surfaces; all dispensed drops rolled off at certain degrees on the SMAB surfaces;

iii) $5 \mathrm{~h}, 5 / 16$ of the dispensed drops rolled off immediately while $1 / 16$ of the dispensed drops pinned on the SMB surfaces; all dispensed drops rolled off at certain degrees on the SMAB surfaces;

iv) $20 \mathrm{~h}$, only one dispensed drop rolled off on the SMB surfaces; $1 / 7$ of the dispensed drops rolled off immediately while no dispensed drops pinned on the SMAB surfaces.

The sessile drop measurement is more useful for measuring the wetting property of a smooth and homogeneous surface. As known, the wood is hygroscopic and swellable and its surfaces are heterogeneous, which makes the wetting process complex especially when using a polar liquid. In the study of the wettability of the SMB and $\mathrm{SMAB}$, the static contact angles and roll-off angles can only represent the specific spots as the surface-modified wood samples are still heterogeneous. The Wilhelmy plate method is regarded as a more accurate method for evaluating the wetting property of wood as a large area can be covered during the measurement and an average value is obtained which enables a high reproducibility. The multicycle 
Wilhelmy plate measurement allows the study of the dynamic wetting and dewetting of the superhydrophobic wood, as well. Furthermore, the liquid uptake of wood can be achieved in the repeated immersion cycles.

Figure 6 shows results from the 100-cycle Wilhelmy plate measurements for selected birch, acetylated birch, as well as SMB and SMAB samples. The birch and acetylated birch showed an initial $\theta_{\mathrm{a}}$ of $93^{\circ}$ and $75^{\circ}$, respectively. However, the $\theta_{\mathrm{r}}$ value in all cycles and the $\theta_{\mathrm{a}}$ in all subsequent cycles were zero, suggesting the wood surfaces were completely wetted in water in the absence of surface modification. The force detected after the removal of the sample from the liquid increased with increasing immersion cycle and this was caused by water sorption. The SMB and SMAB showed an initial $\theta_{a, 1}$ of $124^{\circ}$ and $146^{\circ}$, and an initial $\theta_{r, 1}$ of $82^{\circ}$ and $90^{\circ}$, respectively, indicating the water repellence of the wood surfaces was effectively improved by the silicone nanofilaments. Moreover, only a small increase in the detected force was observed for both SMB and SMAB when removing the sample from water after 100 cycles.
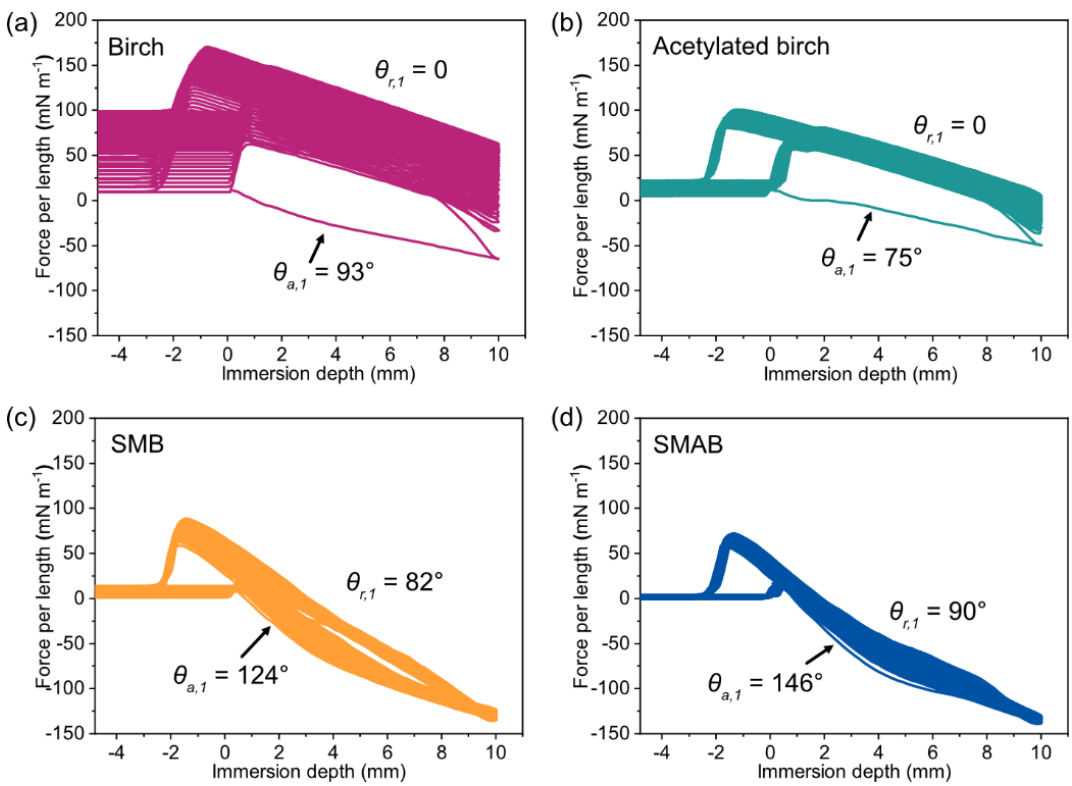

Figure 6. Force per perimeter length as a function of sample position for 100-cycle Wilhelmy plate measurements for (a) birch, (b) acetylated birch and (c) SMB and (d) $\mathrm{SMAB}$ prepared at $5 \mathrm{~h}$. 
Table 2 summarizes the $\theta_{a}, \theta_{r}$ and contact angle hysteresis (CAH) for the SMB and SMAB at specific cycles. The $\theta_{a}$ and $\theta_{r}$ show a decreasing trend with increasing cycles and the largest drop was observed in the first 10 cycles for both the SMB and SMAB samples. Furthermore, the SMAB showed higher $\theta_{a}$ s and $\theta_{r}$ s than those of the SMB. Meanwhile, it showed lower CAHs. Therefore, the SMAB shows a greater liquid repellence than the SMB.

Table 2. Advancing angle $\theta_{\mathrm{a}}$ and receding angle $\theta_{\mathrm{r}}$ and contact angle hysteresis $\mathrm{CAH}$ with standard deviations for SMB and SMAB samples prepared at $5 \mathrm{~h}$ at specific cycles.

\begin{tabular}{ccccccc}
\hline \multirow{2}{*}{ Cycle No. } & \multicolumn{3}{c}{ SMB } & \multicolumn{3}{c}{ SMAB } \\
\cline { 2 - 6 } & $\theta_{\mathrm{a}}\left(^{\circ}\right)$ & $\theta_{\mathrm{r}}\left(^{\circ}\right)$ & $\mathrm{CAH}\left(^{\circ}\right)$ & $\theta_{\mathrm{a}}\left(^{\circ}\right)$ & $\theta_{\mathrm{r}}\left(^{\circ}\right)$ & $\mathrm{CAH}\left(^{\circ}\right)$ \\
\hline 1 & $122 \pm 3$ & $70 \pm 11$ & $52 \pm 11$ & $154 \pm 8$ & $89 \pm 7$ & $65 \pm 9$ \\
10 & $93 \pm 23$ & $48 \pm 22$ & $45 \pm 6$ & $109 \pm 12$ & $72 \pm 16$ & $38 \pm 14$ \\
50 & $89 \pm 27$ & $36 \pm 32$ & $53 \pm 5$ & $90 \pm 17$ & $67 \pm 21$ & $23 \pm 4$ \\
100 & $87 \pm 27$ & $37 \pm 33$ & $51 \pm 6$ & $85 \pm 15$ & $63 \pm 22$ & $22 \pm 7$ \\
\hline
\end{tabular}

Figure 7 shows the water uptake versus the immersion cycle obtained from the 100cycle Wilhelmy curves. The water uptake of unmodified birch increased dramatically with the increasing immersion cycles, approaching $86 \pm 6 \mathrm{wt} \%$ after 100 cycles. The acetylated birch showed a much lower water uptake rate, leading to final water uptake of $15 \pm 3 \mathrm{wt} \%$, almost 6 times lower than that of the birch wood. The SMB exhibited an even slower water uptake behavior as a result of the superhydrophobic coating, ending at $10 \pm 1 \mathrm{wt} \%$ after 100 cycles, which was 8.6 and 1.5 times lower than that of the birch and acetylated birch, respectively. This result suggests that the surface modification of wood by silicone nanofilaments shows more pronounced improvement regarding the water-resistance property of wood than the acetylation of wood. The water uptake of SMAB was as low as $3 \pm 1 \mathrm{wt} \%$ after 100 cycles, which was about 29, 5 and 3 times lower than that of the birch, acetylated birch and SMB, respectively. To conclude, remarkably reduced water uptake of wood was obtained by combining the acetylated wood with the superhydrophobic coating. 


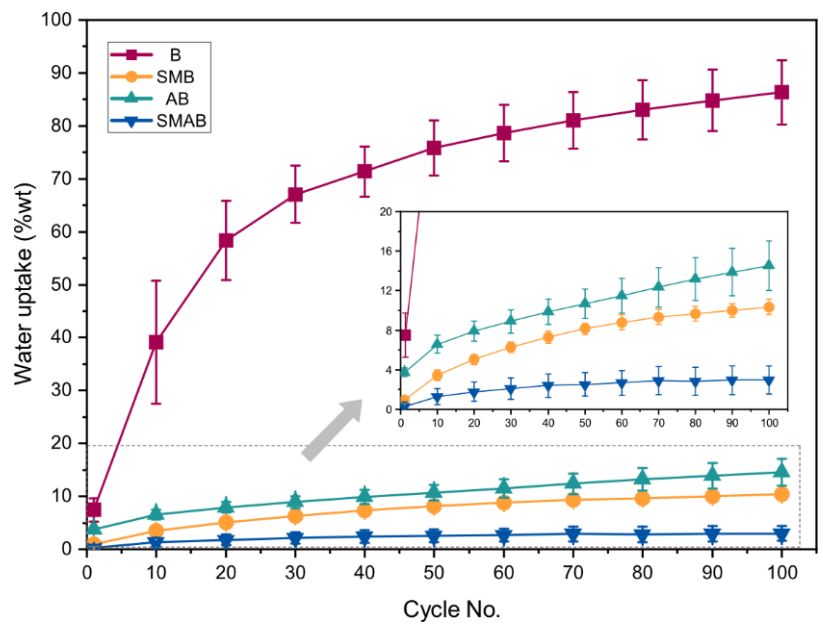

Figure 7. Water uptake from multi-cycle Wilhelmy measurements with standard deviation as a function of cycle number for birch (B), acetylated birch (AB) and $\mathrm{SMB}$ and SMAB samples prepared at $5 \mathrm{~h}$.

Unmodified wood is hygroscopic due to its porous structure and the hydrophilic nature of its components. The liquid sorption process for the unmodified wood includes the wetting of the surfaces, the gradually filling of the wood voids through capillaries and the continuous diffusion and swelling in the wood structures (Sedighi Moghaddam et al. 2014). As a result, the water uptake of the unmodified wood can be high after long-time contact with water. For acetylated wood, the wood affinity for water is reduced mainly due to the reduction of primary sorption sites and the decrease of the volume in the wood cell walls which is available to water (Popescu et al. 2013, Rowell 2014). But the acetylated birch wood is still hydrophilic and the porosity of the wood is not changed. Therefore, the water can still be absorbed into the porous structures in wood. It was reported the acetylation mainly reduced the liquid uptake by reducing the swelling (Sedighi Moghaddam et al. 2016). For the surface-modified non-acetylated wood, the superhydrophobic coating layer acts as a barrier, effectively repelling the water from the wood surfaces. Due to the diffusion effect, SMB wood can still absorb water. In addition, solubility in the nanofilaments layer for water can contribute to the liquid penetration, as suggested (Yin et al. 2020). The wood affinity for water inside the porous wood structures is not changed compared to the unmodified wood. Therefore, the water uptake of the SMB increased gradually upon long-time contact with water. In the 100-cycle Wilhelmy measurement, the SMB wood showed lower water uptake than the acetylated birch 
wood, suggesting that the silicone nanofilaments coating is more efficient in repelling water than the acetylation. For the surface-modified acetylated wood, on the one hand, it is able to repel water from the surfaces due to the superhydrophobic silicone nanofilaments layer; on the other hand, it shows low affinity for water sorption owing to the acetylation. Therefore, extremely low water uptake was obtained for the SMAB wood.

As known, the acetylated wood shows good resistance against fungi and mechanical properties, and superhydrophobic surfaces generally show good selfcleaning properties. These aspects were not investigated in this study, but it is believed that the surface-modified acetylated wood can also bring such functional properties to the wood.

\section{Conclusions}

The applied non-fluorine surface modification, even at shorter reaction times, results in static water contact angles greater than $160^{\circ}$ and low roll-off angles on both the birch and the acetylated birch samples, i.e. a superhydrophobic behavior. Dynamic wettability was studied by a multicycle Wilhelmy plate method, which showed a remarkably low water uptake of the surface-modified acetylated samples in the repeated wetting cycles in water, about 29, 5 and 3 times lower than that of the birch, acetylated birch and surface-modified birch, respectively. The low water uptake of surface-modified acetylated wood is caused by a combined effect of high water repellence of the surface and the low affinity for water sorption of the acetylated (bulk-modified) cell-wall. In addition, the applied surface modification brings only small color changes on the wood surfaces, especially for the acetylated samples.

\section{Acknowledgments}

We thank Formas research council for funding the project "Durable water-, oil- and soil repellent wood for outdoor applications via smart surface modification", grant no. 2016-01362. The project was also supported by the Vinnova project 2017-02712 "Bärande utomhusträ" within the BioInnovation program.

\section{References}

Accsys. What is acetylation? How we enhance nature. [cited 202028 September]; Available from: https://www.accsysplc.com/products/what-isacetylation/. 
Artus, G.R., Olveira, S., Patra, D., Seeger, S. (2017) Directed in situ shaping of complex nano- and microstructures during chemical synthesis. Macromol Rapid Commun. 38.

Artus, G.R., Seeger, S. (2014) One-dimensional silicone nanofilaments. Adv Colloid Interface Sci. 209:144-62.

Barcík, Š., Gašparík, M., Razumov, E.Y. (2015) Effect of temperature on the color changes of wood during thermal modification. Cellulose chemistry and technology. 49:789-798.

Beck, G., Thybring, E.E., Thygesen, L.G. (2018) Brown-rot fungal degradation and de-acetylation of acetylated wood. International Biodeterioration \& Biodegradation. 135:62-70.

Bongers, F., Uphill, S. (2019) Performance of acetylated wood in aquatic applications. International Wood Products Journal. 10:95-101.

Bryne, L.E., Wålinder, M.E. (2010) Ageing of modified wood. Part 1: Wetting properties of acetylated, furfurylated, and thermally modified wood. Holzforschung. 64:295-304.

Cademartori, P.H.G.D., Stafford, L., Blanchet, P., Magalhães, W.L.E., Muniz, G.I.B.D. (2017) Enhancing the water repellency of wood surfaces by atmospheric pressure cold plasma deposition of fluorocarbon film. RSC Advances. 7:2915929169.

Chai, Y., Liu, J., Wang, Z., Zhao, Y. (2017) Dimensional stability and mechanical properties of plantation poplar wood esterified using acetic anhydride. BioResources. 12:912-922.

Chen, Y., Fan, Y., Gao, J., Stark, N.M. (2012) The effect of heat treatment on the chemical and color change of black locust (robinia pseudoacacia) wood flour. BioResources. 7:1157-1170.

Cunha, A.G., Freire, C., Silvestre, A., Pascoal Neto, C., Gandini, A., Belgacem, M.N., Chaussy, D., Beneventi, D. (2010) Preparation of highly hydrophobic and lipophobic cellulose fibers by a straightforward gas-solid reaction. J Colloid Interface Sci. 344:588-95.

Gao, L., Lu, Y., Zhan, X., Li, J., Sun, Q. (2015) A robust, anti-acid, and hightemperature-humidity-resistant superhydrophobic surface of wood based on a modified tio 2 film by fluoroalkyl silane. Surface and Coatings Technology. 262:3339.

Guo, H., Fuchs, P., Casdorff, K., Michen, B., Chanana, M., Hagendorfer, H., Romanyuk, Y.E., Burgert, I. (2017) Bio-inspired superhydrophobic and omniphobic wood surfaces. Advanced Materials Interfaces. 4:1600289.

Hansmann, C., Schwanninger, M., Stefke, B., Hinterstoisser, B., Gindl, W. (2004) Uv-microscopic analysis of acetylated spruce and birch cell walls. Holzforschung. 58:483-488.

Hill, C.A. Wood modification: Chemical, thermal and other processes. John Wiley \& Sons, (2006).

Hung, K.-C., Wu, T.-L., Chen, Y.-L., Wu, J.-H. (2016) Assessing the effect of wood acetylation on mechanical properties and extended creep behavior of wood/recycled-polypropylene composites. Construction and Building Materials. 108:139-145. 
Joffre, T., Segerholm, K., Persson, C., Bardage, S.L., Hendriks, C.L.L., Isaksson, P. (2017) Characterization of interfacial stress transfer ability in acetylation-treated wood fibre composites using x-ray microtomography. Industrial Crops and Products. 95:43-49.

Källbom, S., Moghaddam, M.S., Wålinder, M.E. (2018) Liquid sorption, swelling and surface energy properties of unmodified and thermally modified scots pine heartwood after extraction. Holzforschung. 72:251-258.

Laine, K., Segerholm, K., Wålinder, M., Rautkari, L., Hughes, M., Lankveld, C. (2016) Surface densification of acetylated wood. European Journal of Wood and Wood Products. 74:829-835.

Lundquist, K. (1970) Acid degradation of lignin. Acta Chem. Scand. 24.

Meyer-Veltrup, L., Brischke, C., Alfredsen, G., Humar, M., Flæte, P.-O., Isaksson, T., Brelid, P.L., Westin, M., Jermer, J. (2017) The combined effect of wetting ability and durability on outdoor performance of wood: Development and verification of a new prediction approach. Wood Science and Technology. 51:615637.

Mohammed-Ziegler, I., Tánczos, I., Hórvölgyi, Z., Agoston, B. (2008) Waterrepellent acylated and silylated wood samples and their surface analytical characterization. Colloids and Surfaces A: Physicochemical and Engineering Aspects. 319:204-212.

Olveira, S., Stojanovic, A., Seeger, S. (2018) Systematic parametric investigation on the cvd process of polysiloxane nano-and microstructures. Journal of Nanoparticle Research. 20:307.

Pandit, S.K., Tudu, B.K., Mishra, I.M., Kumar, A. (2020) Development of stain resistant, superhydrophobic and self-cleaning coating on wood surface. Progress in Organic Coatings. 139:105453.

Popescu, C.-M., Hill, C.a.S., Curling, S., Ormondroyd, G., Xie, Y. (2013) The water vapour sorption behaviour of acetylated birch wood: How acetylation affects the sorption isotherm and accessible hydroxyl content. Journal of Materials Science. 49:2362-2371.

Pries, M., Wagner, R., Kaesler, K.-H., Militz, H., Mai, C. (2013) Acetylation of wood in combination with polysiloxanes to improve water-related and mechanical properties of wood. Wood science and technology. 47:685-699.

Ringman, R., Pilgård, A., Richter, K. (2020) Brown rot gene expression and regulation in acetylated and furfurylated wood: A complex picture. Holzforschung. 74:391-399.

Rowell, R. (2014) Acetylation of wood-a review. International Journal of Lignocellulosic Products. 1:1-27.

Rowell, R., Simonson, R., Hess, S., Plackett, D., Cronshaw, D., Dunningham, E. (1994) Acetyl distribution in acetylated whole wood and reactivity of isolated wood cell-wall components to acetic anhydride. Wood and fiber science. 26:11-18.

Sedighi Moghaddam, M., Claesson, P.M., Wålinder, M.E.P., Swerin, A. (2014) Wettability and liquid sorption of wood investigated by wilhelmy plate method. Wood Science and Technology. 48:161-176.

Sedighi Moghaddam, M., Heydari, G., Tuominen, M., Fielden, M., Haapanen, J., Mäkelä, J.M., Wålinder, M.E.P., Claesson, P.M., Swerin, A. (2016) 
Hydrophobisation of wood surfaces by combining liquid flame spray (lfs) and plasma treatment: Dynamic wetting properties. Holzforschung. 70.

Sedighi Moghaddam, M., Walinder, M.E., Claesson, P.M., Swerin, A. (2013) Multicycle wilhelmy plate method for wetting properties, swelling and liquid sorption of wood. Langmuir. 29:12145-53.

Sedighi Moghaddam, M., Wålinder, M.E.P., Claesson, P.M., Swerin, A. (2016) Wettability and swelling of acetylated and furfurylated wood analyzed by multicycle wilhelmy plate method. Holzforschung. 70:69-77.

Sundqvist, B., Colour changes and acid formation in wood during heating, (2004), Luleå tekniska universitet.

Swerin, A., Wåhlander, M. On fundamentals and applications of superhydrophobicity in papermaking and packaging. in XIVth Fundamental Research Symposium, Advances in Pulp and Paper Research, Fundamental Research Committee. 2009.

Tang, Z., Xie, L., Hess, D.W., Breedveld, V. (2016) Fabrication of amphiphobic softwood and hardwood by treatment with non-fluorinated chemicals. Wood Science and Technology. 51:97-113.

Teisala, H., Butt, H.J. (2018) Hierarchical structures for superhydrophobic and superoleophobic surfaces. Langmuir.

Tuominen, M., Teisala, H., Haapanen, J., Mäkelä, J.M., Honkanen, M., Vippola, M., Bardage, S., Wålinder, M.E.P., Swerin, A. (2016) Superamphiphobic overhang structured coating on a biobased material. Applied Surface Science. 389:135-143.

Tuteja, A., Choi, W., Mckinley, G.H., Cohen, R.E., Rubner, M.F. (2011) Design parameters for superhydrophobicity and superoleophobicity. MRS Bulletin. 33:752758.

Wang, Y., Tang, Z., Lu, S., Zhang, M., Liu, K., Xiao, H., Huang, L., Chen, L., $\mathrm{Wu}, \mathrm{H} ., \mathrm{Ni}, \mathrm{Y}$. (2020) Superhydrophobic wood grafted by poly(2(perfluorooctyl)ethyl methacrylate) via atrp with self-cleaning, abrasion resistance and anti-mold properties. Holzforschung. 74:799-809.

Wålinder, M.E., Ström, G. (2001) Measurement of wood wettability by the wilhelmy method. Part 2. Determination of apparent contact angles. Holzforschung. 55:33-41.

Yin, H., Sedighi Moghaddam, M., Tuominen, M., Eriksson, M., Järn, M., Dédinaitè, A., Wålinder, M., Swerin, A. (2020) Superamphiphobic plastrons on wood and their effects on liquid repellence. Materials \& Design. 195:108974.

Zimmermann, J., Reifler, F.A., Fortunato, G., Gerhardt, L.-C., Seeger, S. (2008) A simple, one-step approach to durable and robust superhydrophobic textiles. Advanced Functional Materials. 18:3662-3669. 